\title{
To the planets on a shoestring
}

\author{
Small space probes can thumb a ride into space \\ and then hurl themselves around the Solar \\ System using orbital gymnastics - meaning \\ that you no longer need bottomless pockets \\ to do planetary science. Robert Adler talks to \\ the thrifty engineers who are making it happen.
}

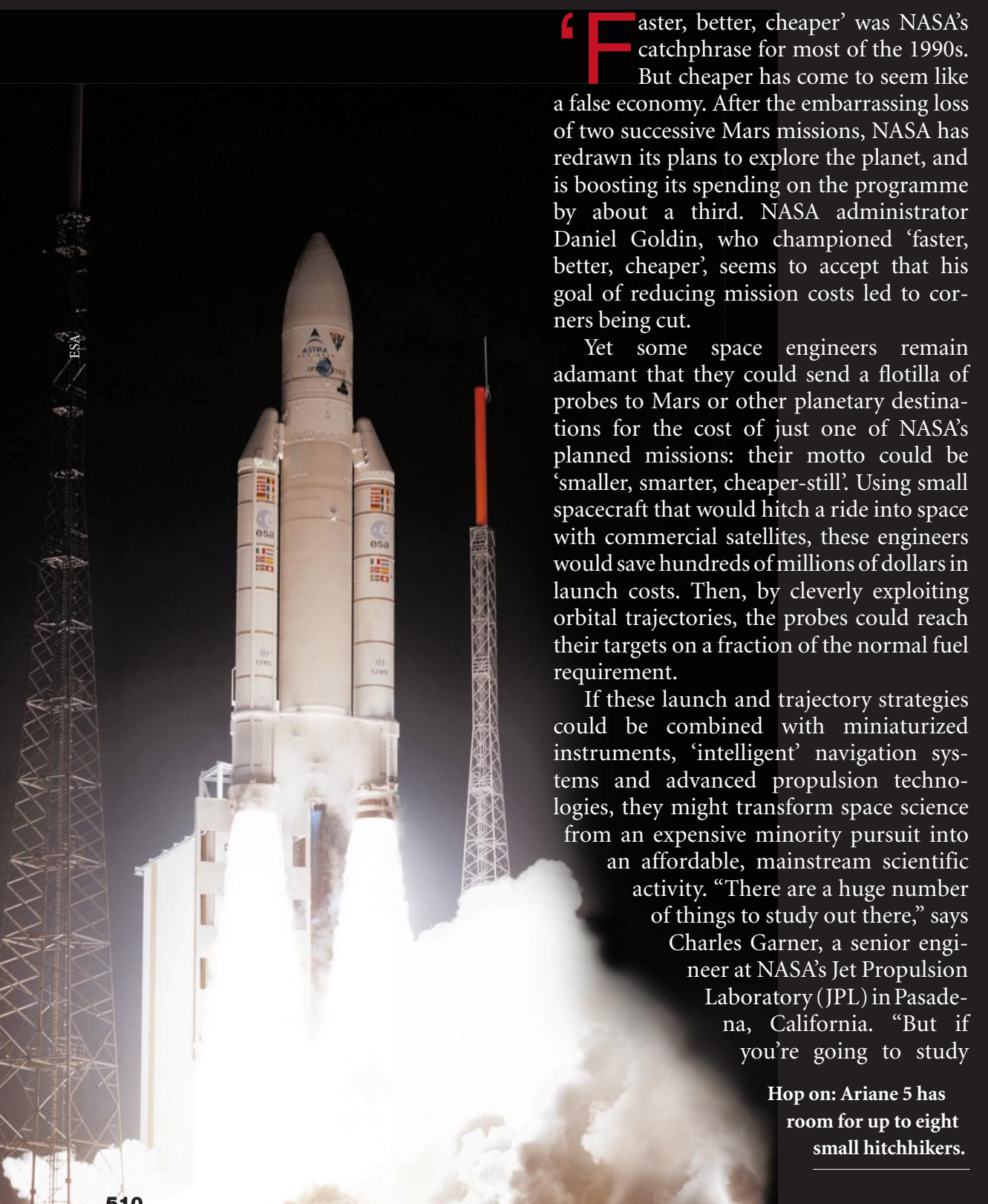

them to any substantial degree, you've got to have cheap access to space."

Getting into orbit around the Earth can account for up to half of the cost of a planetary science mission. And as long as this is done using chemical rockets, the basic economics are rigid. "Launch costs have not changed significantly in the past 20 years," says Maggie Jones, manager of the small satellite programme of Ball Aerospace, a company in Boulder, Colorado. "So something else has to change."

Given that the cost of getting into space increases with a craft's mass, the most obvious thing to change is a probe's size. It took an excessive amount of cash to get some of the huge spacecraft designed by NASA in the 1980s off the launch pad. Galileo, for instance, now completing its mission to Jupiter and its moons, tipped the scales at 3,881 kilograms; its 1989 launch, on the space shuttle Atlantis, cost $\$ 550$ million.

\section{Hitchhilker's guide}

When he took over at NASA in 1992, Goldin recognized the problem. Such bloated spacecraft put too many eggs in one basket - as the loss of the $\$ 1$ billion Mars Observer probe in 1993 demonstrated. Subsequent Mars missions were slimmed down: Mars Global Surveyor, for instance, now orbiting the Red Planet, had a mass of some $1,000 \mathrm{~kg}$ at launch. But to the 'smaller, smarter, cheaper-still' brigade — who are working on spacecraft a fraction of this size - Surveyor and its kind are still heavyweights.

With smaller spacecraft, costs can be slashed by hitching a ride into space on a commercial satellite launch. Several start-up companies hope to exploit this market. For example, EUROCKOT, based in Bremen, Germany, is using modified Soviet SS-19ballistic missiles, and plans its first launch in late 
2001. The rockets' main job will be to launch commercial satellites of around $350 \mathrm{~kg}$. But the company also offers a 'LaunchaPiggy' service, with piggyback slots for smaller craft costing as little as $\$ 10,000$ per kilogram. If each of the piggies weighs $50 \mathrm{~kg}$, seven could go into orbit at a time.

A few of the big players in launch services already offer piggyback rides. Europe's Arianespace consortium has launched 24 small satellites, weighing up to $50 \mathrm{~kg}$ each, on its Ariane 4 rockets. The larger Ariane 5, which began commercial operations in December 1999, can carry up to eight $120-\mathrm{kg}$ piggyback payloads per launch. Alternatively, two of the piggyback units can be combined to carry a single $240-\mathrm{kg}$ payload. Because the operator of the main payload - which is usually a large communications satellite covers the launch costs, the hitchhikers can fly for just one or two million dollars.

\section{Satellites with altitude}

So far, piggyback launches have only put small satellites into Earth orbit. But Ariane 5 has started to fire the imaginations of engineers interested in exploring the planets, as a piggyback slot of $240-\mathrm{kg}$ could ferry a respectable package of scientific instruments to Mars or beyond. "Ariane 5 is very exciting for planetary missions," says Jacques Blamont, adviser to the directorgeneral of CNES, the French space agency.

Ariane 5 leaves its payloads in a geosynchronous transfer orbit (GTO). These are highly elliptical, typically coming within a few hundred kilometres of the Earth's surface at their lowest point, or perigee, but extending out to some $36,000 \mathrm{~km}$ from Earth at their highest point, or apogee. At this altitude, objects in a circular orbit remain over the same point on the Earth's surface at al times - hence the term geosynchronous. Telecoms satellites move from an elliptical GTO to geosynchronous orbit by using thrusters to boost their altitude at perigee.

Blasting straight from a GTO to the planets would take huge amounts of fuel. But it is possible to leave a GTO much more efficiently and head off in almost any direction. The secret is to use a trick thought up in the late 1980s by Edward Belbruno, an applied mathematician who specializes in celestial dynamics, now at Princeton University in New Jersey, and James Miller, an expert in spacecraft navigation at the JPL.

Belbruno and Miller realized that modest amounts of rocket power could increase the apogee of a spacecraft's orbit until it lies several hundreds of thousands of kilometres from the Earth. At such distances, explains Belbruno, probes can enter a region of space known as the Weak Stability Boundary, where the gravitational pulls of the Earth, Moon and Sun almost cancel one another out. In this zone, the mathematics of chaos rules, and a gentle rocket burn can radically alter a spacecraft's trajectory. "It's like a drunk walking down the street," says Belbruno. "At any given moment, he can veer off in any direction."

The calculations needed to achieve a particular result are fiendishly complicated. But two space salvage operations have shown that these spacefaring drunks can be steered successfully to their destination. The first involved a Japanese spacecraft called Hiten, launched in 1990, which was supposed to eject a basketball-sized probe called Hagoromo into lunar orbit. Unfortunately, Hagoromo was lost, and mission controllers turned to Belbruno and Miller's calculations to rescue the mission.

Hiten, parked in an elliptical Earth orbit, did not have enough fuel to get to the Moon by conventional means. But by gradually extending the satellite's orbit until it reached more than a million kilometres beyond the Moon - some 1.4 million kilometres from the Earth - a very small thrust was enough to ease Hiten into lunar orbit in early 1992. "Japan became the third country in history to send a craft to the Moon," says Belbruno, "and the first to demonstrate a Weak Stability Boundary transfer."

The second salvage mission resurrected Asiasat 3, a communications satellite that ended up in a useless low orbit after the fourth stage of its launcher failed on Christmas Day 1997. There it stayed until, in May 1998, engineers with Hughes Electronics in El Segundo, California, boosted its apogee to take it just beyond the Moon. After two lunar swingbys, the satellite's thrusters fired, slowing it and altering its trajectory as it swung back towards our planet. Earth's gravity then pulled it into a useful orbit. Renamed HGS-1, the satellite is now in commercial use.

Encouraged by these successes, the European Space Agency (ESA) is planning to use a trajectory based on Belbruno and Miller's concepts to move a spacecraft called SMART-1 from Earth to lunar orbit. Sched-

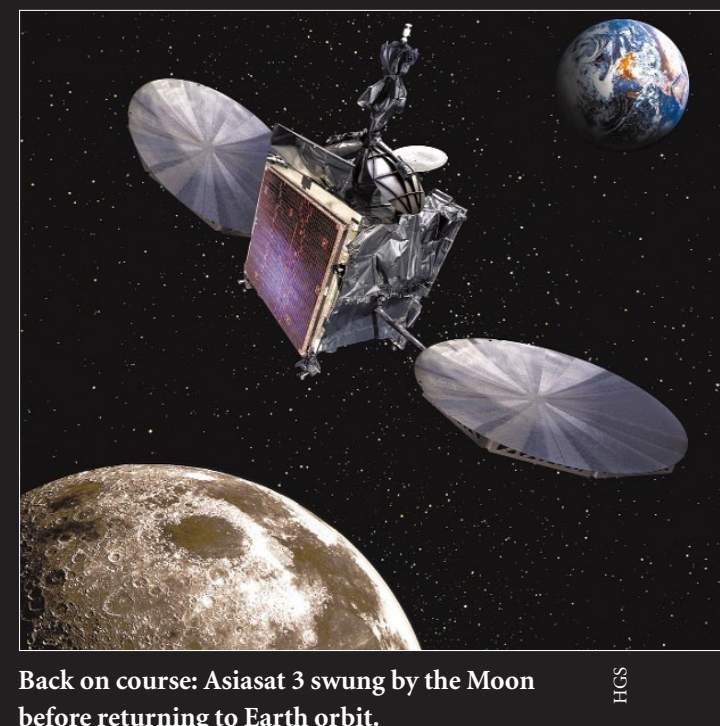
before returning to Earth orbit.

uled for launch by Ariane 5 in October 2002, this craft will take pictures of the Moon's surface while studying its chemical composition using infrared and X-ray spectrometers. SMART-1 is also intended as a testbed for propulsion and navigation technology for future ESA craft including the Bepi Colombo mission to Mercury, scheduled for 2009.

\section{Mars and beyond}

But Blamont wants to use the Weak Stability Boundary to get spacecraft to Mars. Working with experts in celestial dynamics, including Paul Penzo of the JPL, by the late 1990s Blamont had convinced NASA that one of Ariane 5's 240-kg piggyback berths could allow $50 \mathrm{~kg}$ of hardware to reach Mars - enough to yield good scientific returns, given advances in instrument miniaturization. The propulsion system and fuel would account for most of the remaining mass. Penzo devised an elegant strategy to get from GTO to Mars using just three rocket burns and the gravitational pulls of the Earth and Moon (see diagram, below).

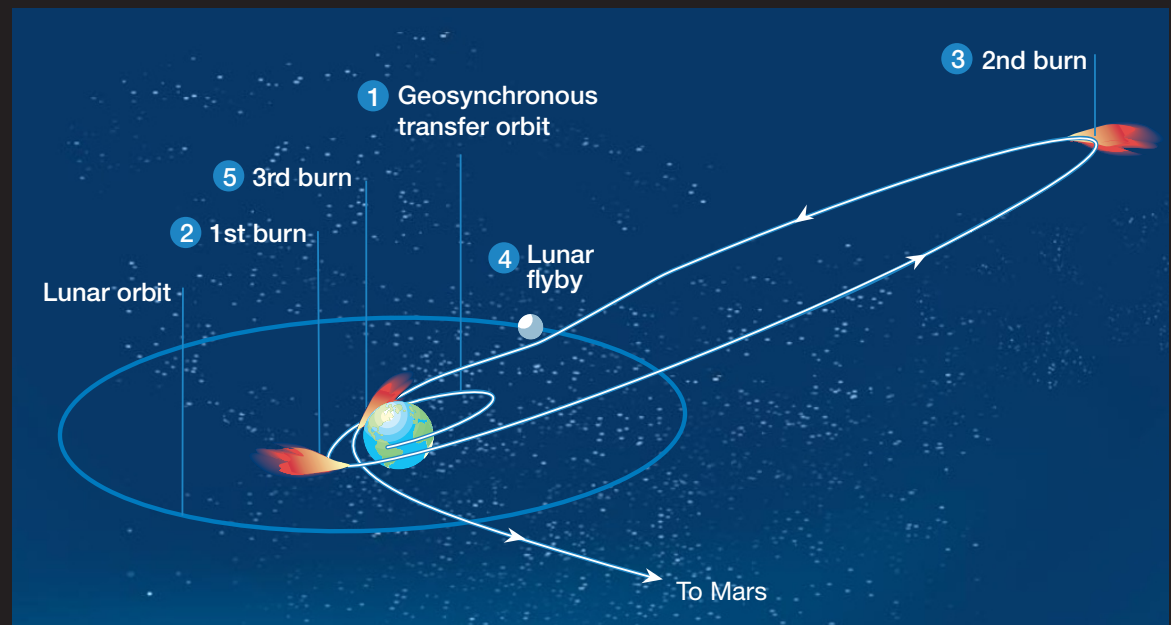

Three burns and you're off: Penzo's fuel-efficient scheme to send a space probe on its way to Mars. 


\section{news feature}

"At first it didn't look feasible," says Penzo. "But after about a year I latched onto a good way to do it." The first burn, at the spacecraft's closest approach to Earth, stretches the orbit beyond the Moon and into the Weak Stability Boundary. A second burn nudges the craft back towards the Moon, whose gravity adjusts its trajectory once more. Finally, the combination of a third burn, again at closest approach to Earth, and the planet's gravitational pull, slings the craft towards Mars.

Trips to Mars must begin at just the right time, if the planet's orbit is not to take it out of a spacecraft's reach. But although piggyback launches must fit in with the timing desired by operators of the primary payload, this is not a problem: the craft can be parked in a GTO until Mars is in the right place. This approach could deliver a series of missions to Mars for as little as $\$ 50$ million each. But in the soul-searching following the losses of Mars Climate Orbiter and Mars Polar Lander in 1999, NASA put the project on hold.

Penzo has also devised a similar way to get to Venus using the Moon's and Earth's gravity. This opens up the possibility of sending piggyback spacecraft to Venus, or using the planet's gravity to swing a probe towards another destination. Despite NASA's cold feet, Kim Leschly, formerly Penzo's project manager at the JPL, believes that the idea of using the Weak Stability Boundary to send small spacecraft to the planets is so clever and cheap that it will be resurrected within the next three years. "I'm certain this concept will revive itself," he says.

The chances of that happening could be enhanced by work on the 'smaller' and 'smarter' aspects of the strategy. Among the key players are engineers at the JPL's Center for Integrated Space Microsystems (CISM), which was established in 1998. Its director, Leon Alkalai, explains that the centre's goal is $\vec{\Xi}$ to miniaturize systems so that they can be

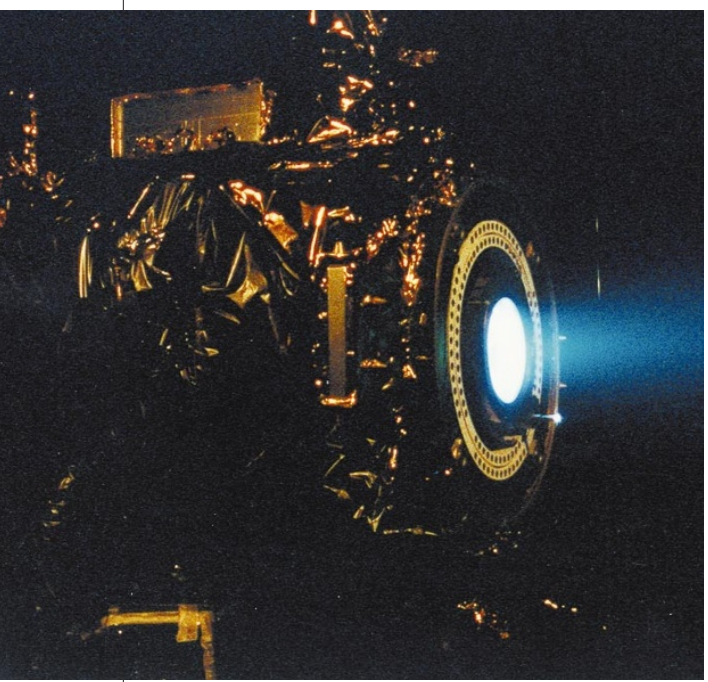

Slow burn: the ion engine on Deep Space 1 uses a fraction of the fuel of a conventional rocket. put onto a series of chips that will allow probes to function autonomously.

The CISM is also applying the techniques used to etch silicon chips to make tiny machines. The centre has already made a gyroscope, vital for controlling a spacecraft's position, that is smaller than a dime. And it is working on devices including star trackers, accelerometers and navigation systems, plus power, command and control, communications, and data-handling units. "These will all be miniaturized to chip-level subsystems, whereas in the past they would have been boxes," says Alkalai. "We're talking about at least an order of magnitude smaller."

\section{A spacecraft on a chip}

Alkalai hopes to fly technology demonstration experiments by 2006. By 2012, he expects to see spacecraft powered and managed by CISM-designed chips exploring the moons of Jupiter or Saturn, or fetching material from a comet back to Earth. And in the longer term, he plans to explore revolutionary computing strategies to create "a thinking spacecraft", able to integrate the information from multiple sensors, recognize patterns, adapt to rapidly changing environments, and deal with faults or external emergencies.

While the CISM looks to the future, several companies are using today's state-ofthe-art electronics to build low-maintenance craft that need little input from the ground. "People come here and they're horrified because there's nobody in the control room," says Martin Sweeting, chief executive of Surrey Satellite Technology, a British firm affiliated with the University of Surrey in Guildford. The company has put 19 small satellites into Earth orbit since 1981, and is now plotting to send a $420-\mathrm{kg}$ probe to the Moon in 2003. "There's a large science community interested," Sweeting says.

Given that rockets and their fuel can account for more than half of a planetary science probe's mass, finding more efficient propulsion systems is another priority. Many ideas have been proposed. But so far, only one has made the trip from drawing board into space. Solar electric propulsion uses power from a spacecraft's solar panels to ionize a gas, which can then be expelled from a nozzle at high velocity using an electromagnetic field.

Solar electric propulsion made its debut on NASA's Deep Space $1 \mathrm{craft}$, launched in October 1998 and headed for a September 2001 rendezvous with Comet Borrelly. Deep Space 1 is powered by an engine that expels xenon ions at 35,000 metres per second. This high velocity makes the ion engine up to ten times more efficient than a chemical rocket - meaning less fuel and a lighter spacecraft. And although current ion engines generate only a tiny fraction of the thrust of conventional rockets, they compensate by being able to fire for thousands of hours. Encour-

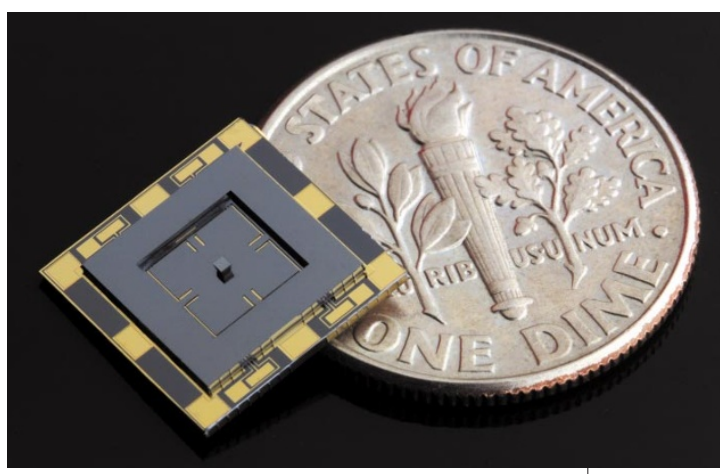

Turn on a dime: NASA's miniature gyroscope.

aged by the success of Deep Space 1, the ESA is planning to deploy a similar engine on SMART-1, which will be used over 17 months to stretch the craft's orbit into the Weak Stability Boundary.

Advances in propulsion and miniaturization could lead to the launch of constellations of tiny craft which would communicate with one another. Testing that concept is the goal of the Space Technology 5 mission, being run from NASA's Goddard Space Flight Center in Greenbelt, Maryland. The plan is to launch, by the end of 2003, three 21.5 -kg satellites that will use micromechanical thrusters to fly in formation, maintaining a close but safe distance from one another with no input from the ground. The spacecraft will monitor the influence of solar activity on the Earth's magnetosphere, the region of space containing charged particles trapped by our planet's magnetic field. "We're blazing the trail," says Doug McLennan, who is managing the mission.

How quickly NASA, the ESA and other space agencies follow that trail remains to be seen. But if the cost of planetary missions can be reduced to a fraction of today's hundreds of millions of dollars, it opens the door to a new kind of space science involving multiple, cheap probes - spreading the risk of failure without breaking the bank. Alkalai is even more bullish, arguing that the 'smarter' aspect will make failures less frequent: "Space exploration will become cheaper and more reliable."

Robert Adler is a writer in Santa Rosa, California.

\section{Web Links:}

LaunchaPiggy

http://www.launchapiggy.com

Arianespace

http://www.arianespace.com

SMART-1

http://sci.esa.int/smart

Center for Integrated Space Microsystems

http://cism.jpl.nasa.gov

Surrey Satellite Technology

http://www.sstl.co.uk

Deep Space 1

http://nmp.jpl.nasa.gov/ds1

Space Technology 5

http://nmp.jpl.nasa.gov/st5/index.html 